\title{
A relação da incidência da Hantavirose com o índice de desmatamento nas regiões sul e sudeste do Brasil no período de 2008 a 2017
}

The relationship between the incidence of Hantavírus and the rate of deforestation inthe Southern and southastern regions of Brazil from 2008 to 2017

La relación de la incidencia de Hantavirus con la tasa de deforestación en las regiones sur y sureste de Brasil en el período de 2008 a 2017

Pamella Ferreira Moura ${ }^{1 *}$, Jacqueline Fátima Martins de Almeida Moraes ${ }^{1 *}$, Raquel Machado Cavalca Coutinho $^{1 *}$, Maria Eleonora Feracin da Silva Picoli ${ }^{1 *}$, Fernando Ananias ${ }^{1 *}$.

\section{RESUMO}

Objetivo: Estudar a incidência da hantavirose comparando ao índice de desmatamento nos estados da região sul e sudeste do Brasil entre 2008 a 2017. Métodos: Estudo observacional, retrospectivo, com coleta dos casos de hantavirose inseridos no banco de dados SINAN NET, disponibilizado pelo DATASUS no período de 2008 a 2017 e os dados do índice de desmatamento disponíveis no Atlas dos Remanescentes florestais da mata atlântica, fundação Mata Atlântica e INPE. Foram analisadas as variáveis: evolução, faixa etária, sexo, ambiente de infecção, zona de infecção e desmatamento. Resultados: Os estados da região sul e sudeste apresentaram 690 casos de hantavirose entre 2008 a 2017. Dentre o total de casos, $51 \%$ estão entre 20 a 49 anos, $77 \%$ masculino, o ambiente mais afetado é o de trabalho com $42 \%$, e $69 \%$ dos casos ocorrem na zona rural. Nos anos de 2011, 2014 e 2017 foi possível observar que a redução significativa do desflorestamento impacta diretamente na redução do número de casos da doença ( $p=0,031, r=0,9969$, Pearson). Conclusão: O desmatamento está diretamente relacionado com as manifestações de hantavirose, sendo necessário um maior incentivo para o desenvolvimento de investigação ecológica e ambiental, e maior conscientização sobre o risco da degradação ambiental.

Palavras-chave: Hantavirose, Desmatamento, Degradação ambiental, Urbanização.

\begin{abstract}
Objective: To study the incidence of hantavirus disease compared to the deforestation index in the southern and southeastern states of Brazil between 2008 and 2017. Methods: Observational, retrospective study, with collection of hantavirus cases entered in the SINAN NET database, made available by DATASUS in the period from 2008 to 2017 and the deforestation index data available in the Atlas of Atlantic Forest Remnants, Atlantic Forest Foundation and INPE. The variables were analyzed: evolution, age group, sex, infection environment, infection zone and deforestation. Results: The states of the southern and southeastern region presented 690 cases of hantavirus between 2008 and 2017. Among the total cases, $51 \%$ are between 20 to 49 years old, $77 \%$ male, the most affected environment is the workplace with $42 \%$, and $69 \%$ of cases occur in rural areas. In the years 2011, 2014 and 2017 it was possible to observe that the significant reduction in deforestation directly impacts the reduction in the number of cases of the disease ( $p=0.031, r=0.9969$, Pearson). Conclusion: Deforestation is directly related to the manifestations of hantavirosis, and more encouragement is needed for the development of ecological and environmental research, and greater awareness about the risk of environmental degradation.
\end{abstract}

Keywords: Hantavirosis, Deforestation, Environmental degradation, Urbanization.

\section{RESUMEN}

Objetivo: Estudiar la incidencia de la enfermedad por hantavirus en comparación con el índice de deforestación en los estados del sur y sureste de Brasil entre 2008 y 2017. Métodos: Estudio observacional, retrospectivo, con recogida de casos de hantavirus introducidos en la base de datos SINAN NET, puesta a disposición por DATASUS en el periodo de 2008 a 2017 y los datos del índice de deforestación disponibles

1 Universidade Paulista (UNIP), Campinas - SP. *E-mail: fernando.ananias@docente.unip.br 
en el Atlas de Restos Forestales Atlánticos, de la Fundación Forestal Atlántica y del INPE. Se analizaron las variables: evolución, grupo de edad, sexo, entorno de infección, zona de infección y deforestación. Resultados: Los estados de la región sur y sureste presentaron 690 casos de hantavirus entre 2008 y 2017. Del total de casos, el $51 \%$ tienen entre 20 y 49 años, el $77 \%$ son hombres, el entorno más afectado es el laboral con un 42\%, y el 69\% de los casos se dan en el ámbito rural. En los años 2011, 2014 y 2017 se pudo observar que la reducción significativa de la deforestación impacta directamente en la reducción del número de casos de la enfermedad ( $p=0,031, r=0,9969$, Pearson). Conclusión: La deforestación está directamente relacionada con las manifestaciones de hantavirosis, siendo necesario un mayor incentivo para el desarrollo de la investigación ecológica y ambiental, y una mayor conciencia sobre el riesgo de la degradación del medio ambiente.

Palabras clave: Hantavirosis, Deforestación, Degradación ambiental, Urbanización.

\section{INTRODUÇÃO}

O gênero Hantavirus, família Bunysviridae, é um patógeno de distribuição mundial tem na região da Mata Atlântica brasileira dois reservatórios roedores principais: Oligoryzomys nigripes e Necromys lasiurus e a infecção humana por hantavírus ocorre pela inalação de aerossóis de excretas de roedores infectados (PRIST PR, et al., 2021).

Os estudos filogenéticos mostram que os hantavírus estão divididos em três grandes clados baseados em qual roedor se apresenta como hospedeiro reservatório: Vírus do Velho Mundo causando febre hemorrágica com síndrome renal (FHSR), que são hospedados por roedores da família Muridae e sub-família Murinae da ordem Rodentia, encontrados predominantemente na Europa e Ásia; Vírus do Novo Mundo responsáveis pela síndrome cardiopulmonar por hantavírus ( $\mathrm{SCH}$ ), encontrados em membros da sub-família Sigmodontinae de ocorrência no continente americano e os hantavírus notificados tanto no Velho como no Novo Mundo, relacionados com doenças leves e transmitidos por roedores da sub-família Arvicolinae (MUNIR N, et al., 2021).

Existem cerca de 40 espécies de hantavírus, 22 delas são consideradas patogênicas para humanos e todas têm roedores como reservatórios. São vírus envelopados com RNA de fita negativa, infectando aproximadamente mais de 200.000 pessoas anualmente em todo o mundo com taxa de mortalidade entre 35\%-40\% (MUNIR N, et al., 2021).

Pacientes infectados pelo hantavírus devem ser diagnosticados o mais rápido possível. O diagnóstico desta infecção envolve testes sorológicos utilizando o método de ELISA (da sigla em inglês: Enzyme Linked Immunosorbent Assay), que é capaz de detectar anticorpos IgM (demonstrando ser uma infecção aguda, recente) e IgG (títulos que mostram ser uma infecção mais crônica) (SEREJO AMD, et al., 2020).

Além do ELISA, muitos outros tipos de exames diagnósticos podem ser usados, incluindo reação em cadeia da polimerase (PCR), o teste de neutralização, teste sorológico por western blotting ("protein blotting ou immunoblotting"), ensaio de imunofluorescência (IFA), entre outras técnicas moleculares usadas na detecção do hantavírus em seres humanos. Esse diagnóstico é importante para que o tratamento sintomático seja iniciado, já que não há tratamento específico efetivo (MUNIR N, et al., 2021).

A observação dos sinais clínicos apresentados pelo paciente infectado por hantavírus é de extrema importância para identificar qual é a forma clínica desenvolvida. Nas Américas, a manifestação ocorre de diferentes formas, desde doença febril aguda inespecífica, até quadros pulmonares e cardiovasculares mais graves e característicos, evoluindo para Síndrome da Angústia Respiratória (SARA). Na Américado do Sul foi notado um comprometimento cardíaco, assim passando a ser designada de Síndrome Cardiopulmonar por Hantavírus (SCPH) (MINISTÉRIO DA SAÚDE, 2021a).

A sintomatologia do paciente está diretamente relacionada a fisiopatologia da doença. O hantavírus infecta principalmente células endoteliais e macrófagos, reconhecendo diferentes receptores do tipo integrinas ( av $\beta 1$, vs, $\alpha 5$ e $\beta 3$ ). As células endoteliais infectadas apresentam antígenos, que ativam o sistema imunológico, particularmente através de macrófagos e linfócitos T CD8 levando a resposta imune excessiva, sendo parte 
central da patogênese da doença. Esse acometimento do endotélio compromete sua permeabilidade, principalmente nos capilares pulmonares, liberando transudato que é responsável pelo quadro de edema pulmonar que o paciente desenvolve (SEREJO AMD, et al., 2020; MUNIR N, et al., 2021).

Pacientes que apresentam formas mais graves da doença necessitam de ventilação mecânica e assistência hemodinâmica e nestes casos, o prognóstico é mais favorável, principalmente quando as medidas de suporte são tomadas precocemente. A grande dificuldade em diagnosticar esses pacientes deve-se a não inclusão da hantavirose no diagnóstico diferencial, fazendo parte das hipóteses diagnósticas em pacientes que tenham quadro clínico pulmonar inespecífico com febre, dispneia, hipoxemia e infiltrado pulmonar difuso. Além disso, evitar-se-ia o subdiagnóstico e poder-se-ia desenvolver melhorias nas táticas de prevenção da doença (SEREJO AMD, et al., 2020).

Atualmente discute-se muito quais são as estratégias de tratamento específico do paciente com hantavirose. Dentre elas, o uso de corticosteroides, inibidores que previnem a ligação de hantavírus às células hospedeiras, anticorpos monoclonais e policlonais como agentes terapêuticos, agentes antivirais como a ribavirina, lactoferrina, favipiravir, vandetanib, vacinação utilizando proteínas virais recombinantes e vacinação com ácido nucleico (DNA) (MUNIR N, et al., 2021).

Embora os primeiros casos de hantavirose datem do século passado, o Brasil teve seu primeiro caso em 1993 na cidade de Juquitiba, localizada noestado de São Paulo. Atualmente, nove variantes de hantavírus já foram identificadas em seres humano, sendo sete delas nos municípios de Araraquara, Juquitiba, Castelo dos Sonhos, Anajatuba, Laguna Negra, Paranoá e Rio Mamoré, associadas à síndrome cardiopulmonar por hantavírus (SCPH) e duas encontradas apenas em roedores nos municípios de Rio Mearim e Jaborá (MINISTÉRIO DA SAÚDE, 2021b).

Nas populações destes roedores a transmissão horizontal é mantida com uma correlação positiva sobre a densidade do reservatório e, portanto, o risco do ser humano se contaminar depende da abundância do reservatório na natureza. Estudos mostram que alguns fatores como condições sociais, a paisagem e o clima estão associados a alta incidência de SCPH na região Neotropical. Um dos grandes efeitos sobre a paisagem é a conversão da vegetação nativa para a agricultura, particularmente o cultivo de cana-de-açúcar que pode alterar a abundância de espécies generalistas roedores que servem como o principal hospedeiro de reservatórios para o SCPH (PRIST PR, et al., 2016; PRIST PR, et al., 2017).

A ocorrência dos casos de SCPH tem relação com as características biológicas dos roedores silvestres, como por exemplo a sua reprodução que, de acordo com as estações do ano poderá ter mais oferta de alimentos. Além disso, outros fatores importantes como a competição entre espécies, alterações climáticas, predação, a floração de bambus e principalmente, o desmatamento inadequado e ocupação desordenada do solo que provoca alterações no ecossistema, levando ao crescimento da população de roedor e aumentando o número de casos (MINISTÉRIO DA SAÚDE, 2021a)

Sendo assim, o objetivo deste trabalho foi relacionar os casos de Hantavirose com o índice de desmatamento que ocorreu nas regiões sul e sudeste do Brasil no período de 2008 a 2017.

\section{MÉTODOS}

Trata-se de um estudo observacional retrospectivo quantitativo, no qual foram analisados os casos de Hantavirose nas regiões Sul e Sudeste do Brasil no período de 2008 a 2017, bem como o índice de desmatamento dessas regiões no mesmo período.

Os dados do agravo foram obtidos por meio de consulta no banco de dados Sistema de Informação de Agravos de Notificação (SINAN NET), disponibilizados pelo Banco de dados do Sistema Único de Saúde (DATASUS), ao passo que os dados do índice de desmatamento foram obtidos através do Atlas das Remanescentes Florestais, disponibilizado pela SOS Mata Atlântica e Instituto Nacional de Pesquisas Espaciais (INPE). Foram excluídas as notificações de agravo e o índice de desmatamento fora do período de estudo e de outras regiões do país que as determinadas no delineamento inicial. 
Foram analisadas variáveis como: evolução da doença, faixa etária, sexo, ambiente de infecção, zona de infecção e índice de desmatamento. Os dados obtidosforam tabulados e avaliados em planilhas no programa Microsoft Excel 2019 e quantificados em frequências absolutas (n), relativas (\%).

Os testes estatísticos foram realizados através do software Graphpad Instat versão 3.0, foi realizado o teste de correlação de Pearson para avaliar as variáveis deíndice de desmatamento e o índice de casos da Hantavirose ao longo dos anos.

As informações utilizadas neste estudo foram obtidas de fontes secundárias, de domínio público, razão pela qual não foram necessárias a submissão e a aprovação pelo Comitê de Ética em Pesquisa.

\section{RESULTADOS}

No período de 2008 a 2017 foi apresentado um total de 690 casos de Hantavirose. Ao analisar os sete estados, Santa Catarina, Minas Gerais e São Paulo juntos somaram $72 \%$ dos casos, enquanto Paraná, Rio Grande do Sul, Rio de Janeiro e Espirito Santo um total de $28 \%$ sendo que a região do Rio de Janeiro apresentou menor número durante o período estudado, com apenas 1 caso. Em relação à evolução da doença, dos 690 casos observados no período de estudo, $57 \%$ evoluíram para cura, enquanto $40 \%$ foram a óbito devido a hantavirose e $1 \%$ causados por outra causa.

Observando a variável faixa etária, verifica-se o predomínio de 20 a 39 anos, correspondendo à 353 casos, enquanto a faixa etária de 1 a 4 anos apresenta o menor índice com apenas 1 caso (Figura 1).

Figura 1 - Distribuição da variável de estudo faixa etária, dos casos de Hantavirose nas regiões Sul e Sudeste de 2008 a 2017.

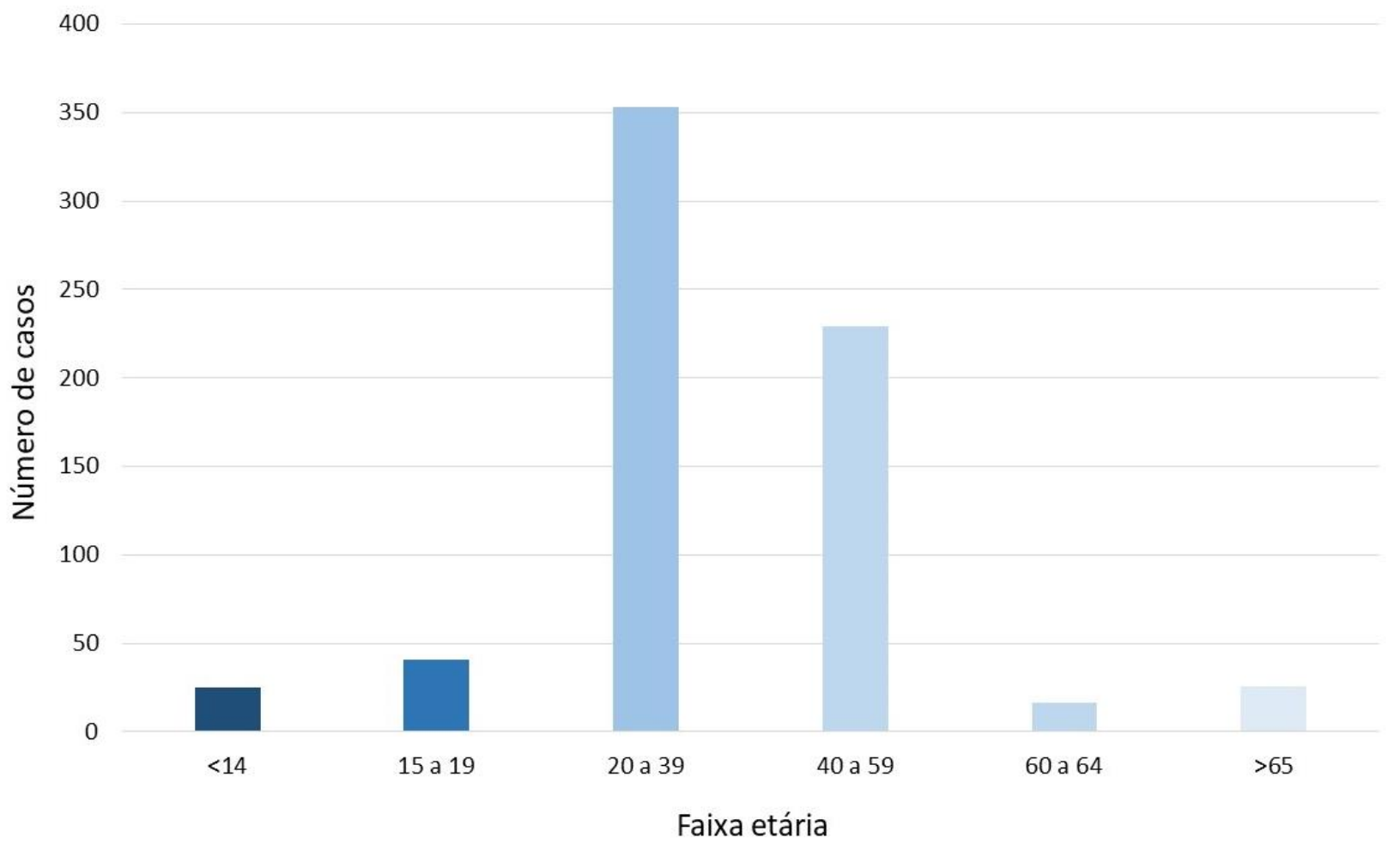

Fonte: Moura PF, et al., 2021; dados extraídos do SINAN.

Considerando as variáveis de estudo como sexo, ambiente de infecção e zona de infecção, é possível observar predominância no sexo masculino com $77 \%$ dos casos, em relação ao ambiente de infecção, destacase o ambiente de trabalho com $42 \%$ dos casos e quanto à zona de infecção dos indivíduos acometidos pela hantavirose, destaca-se a zona rural com $69 \%$ e a zona periurbana com a menor presença de casos com $6 \%$ no total (Tabela 1). 
Tabela 1 - Distribuição das variáveis de estudo sexo, ambiente de infecção e zona de infecção,dos casos de hantavirose nas regiões Sul e Sudeste de 2008 a 2017.

\begin{tabular}{lcc}
\hline Variáveis & N & $\%$ \\
\hline Sexo & & $23 \%$ \\
\hline Feminino & 158 & $77 \%$ \\
Masculino & 532 & \\
\hline Ambiente de infecção & & $16 \%$ \\
\hline Ign/Branco & 110 & $29 \%$ \\
Domiciliar & 199 & $42 \%$ \\
Trabalho & 291 & $9 \%$ \\
Lazer & 64 & $4 \%$ \\
Outro & 26 & $12 \%$ \\
\hline Zona de Infecção & & $13 \%$ \\
\hline Ign/Branco & 80 & $69 \%$ \\
Urbana & 93 & $6 \%$ \\
Rural & 477 & \\
Peri-urbana & 40 & \\
\hline
\end{tabular}

Fonte: Moura PF, et al., 2021; dados extraídos do SINAN.

Em relação à área de desmatamento, as regiões sul e sudeste apresentaram no período estudado, cerca de 90.060 hectares desflorestados. O maior índice de desmatamento aparece nos anos de 2008 a 2010 com $23 \%$, enquanto 2017 apresentao menor índice com 6\%. É possível observar ainda que haja uma tendência de correlação diretamente proporcional do número de casos de hantavirose e os índices de desflorestamento que ocorre nessas regiões, porém não significativa quando comparado todos os anos $(p=0,0881, r=0,7143$, Spearman) (Figura 2).

Figura 2 - Comparação dos casos de hantavirose com o desmatamento nasregiões Sul e Sudeste de 2008 a 2017.

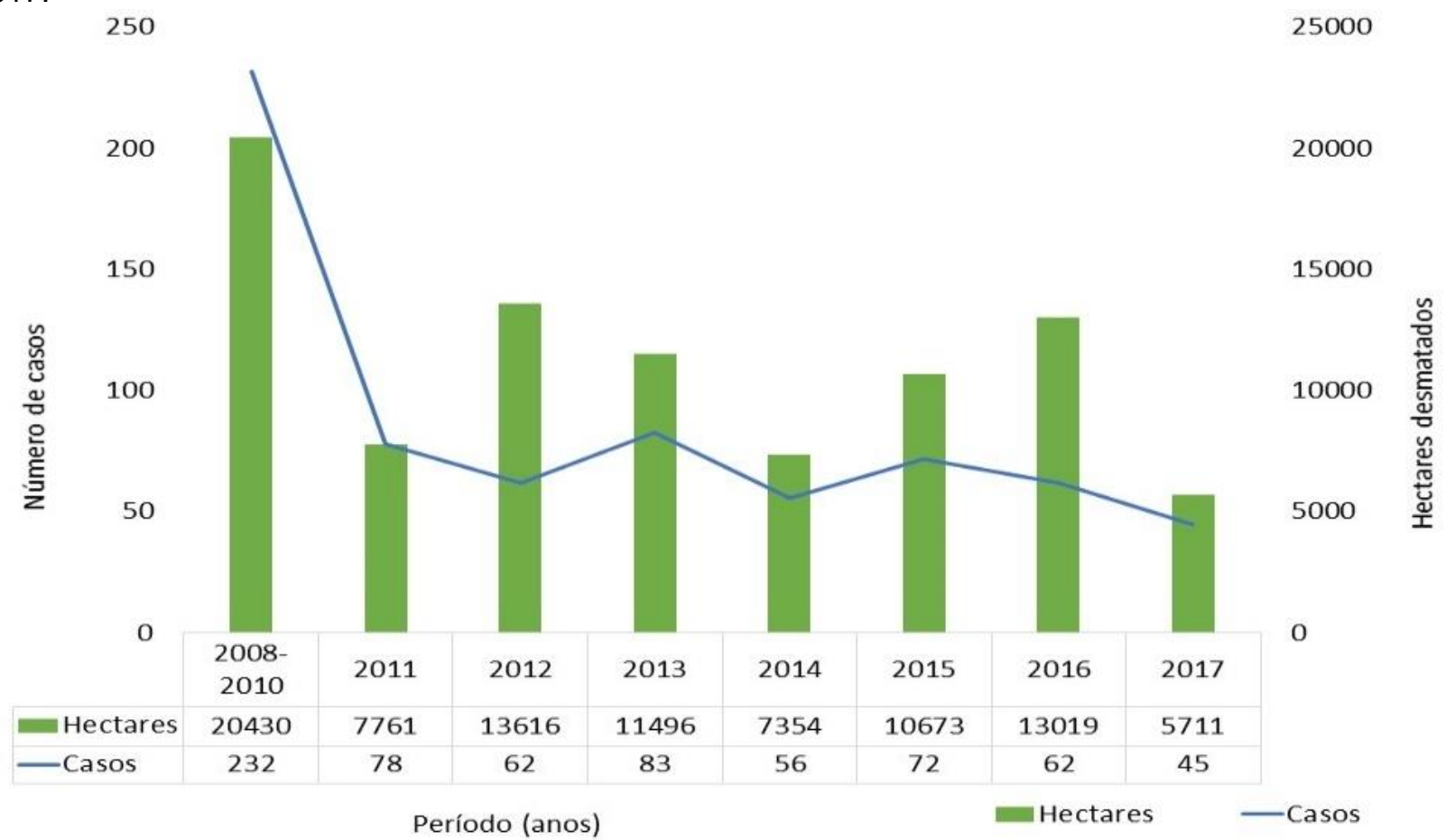

Fonte: Moura PF, et al., 2021; dados extraídos do SINAN.

Porém, nos anos de 2011, 2014 e 2017 foi possível observar que a redução significativa do desflorestamento impacta diretamente na redução do número de casos da doença ( $p=0,031, r=0,9969$, Pearson). E quando analisamos os índices de desmatamento ao longo dos anos a diferença é significativa ( $p$ $<0,0001$; Teste de Qui-quadrado) (Figura 3). 
Figura 3 - Redução dos números de casos da hantavirose comparados com a queda do índice de desmatamento nas regiões Sul e Sudeste no período de 2008 a 2017.

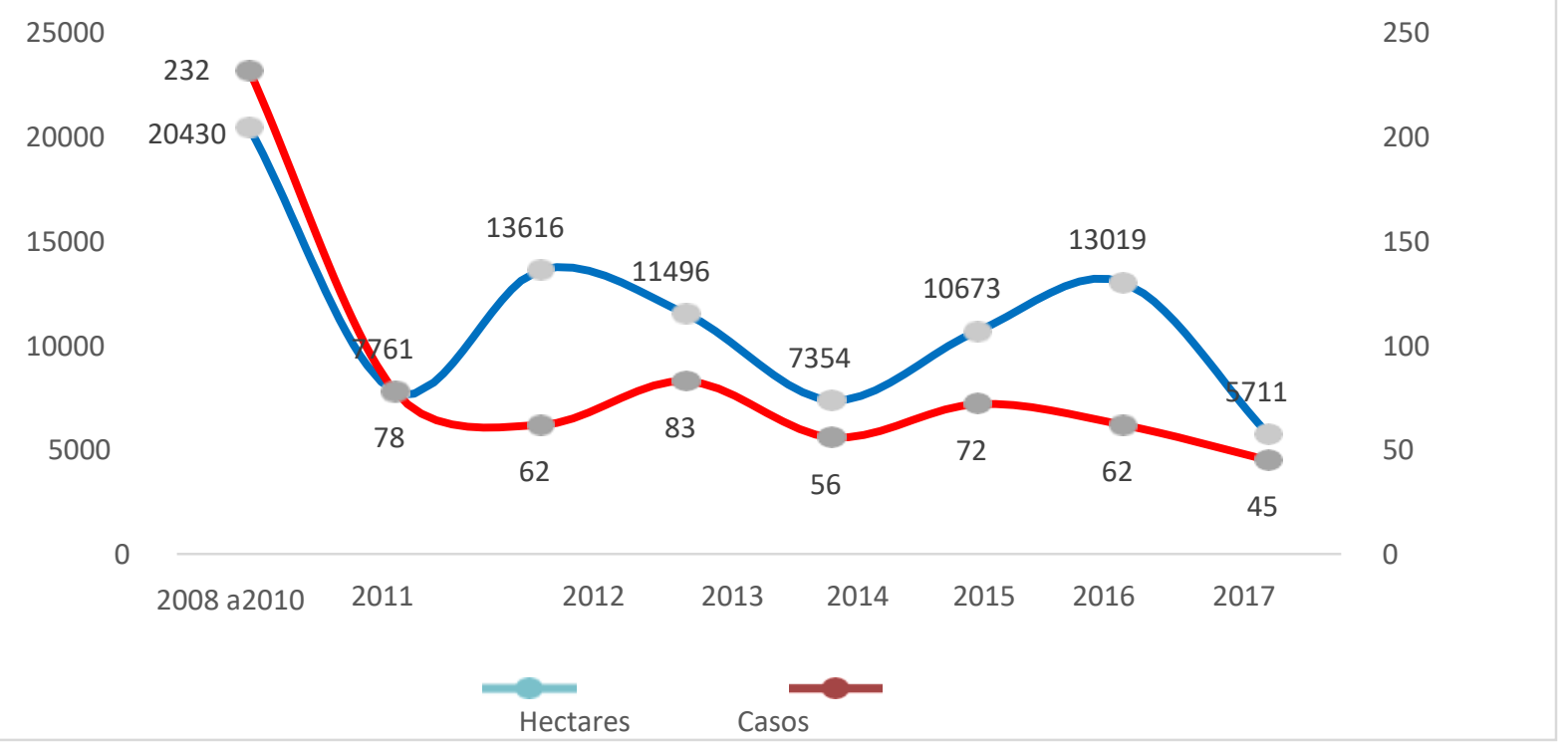

Fonte: Moura PF, et al., 2021; dados extraídos do SINAN.

Considerando a queda do índice de desmatamento do ano de 2017, pode-se observar que todos os estados que compõe a região Sul e Sudeste, com exceção de Santa Catarina, apresentaram diminuição nos casos notificados da hantavirose em 2017 quando comparados com o ano anterior (Figura 4). Dentre os estados avaliados, os que apresentaram menores índices de desflorestamento mostraram menos casos notificados da hantavirose. Rio de Janeiro e Espírito Santo destacam-se com apenas 1\% no índice de desflorestamento, e com a menor presença de casos, com 1 e 0 , respectivamente (Figura 4 e 5).

Figura 4 - Comparativo dos estados que menos desmatam com a redução das notificações da hantavirose nas regiões sul e sudeste de 2008 a 2017.

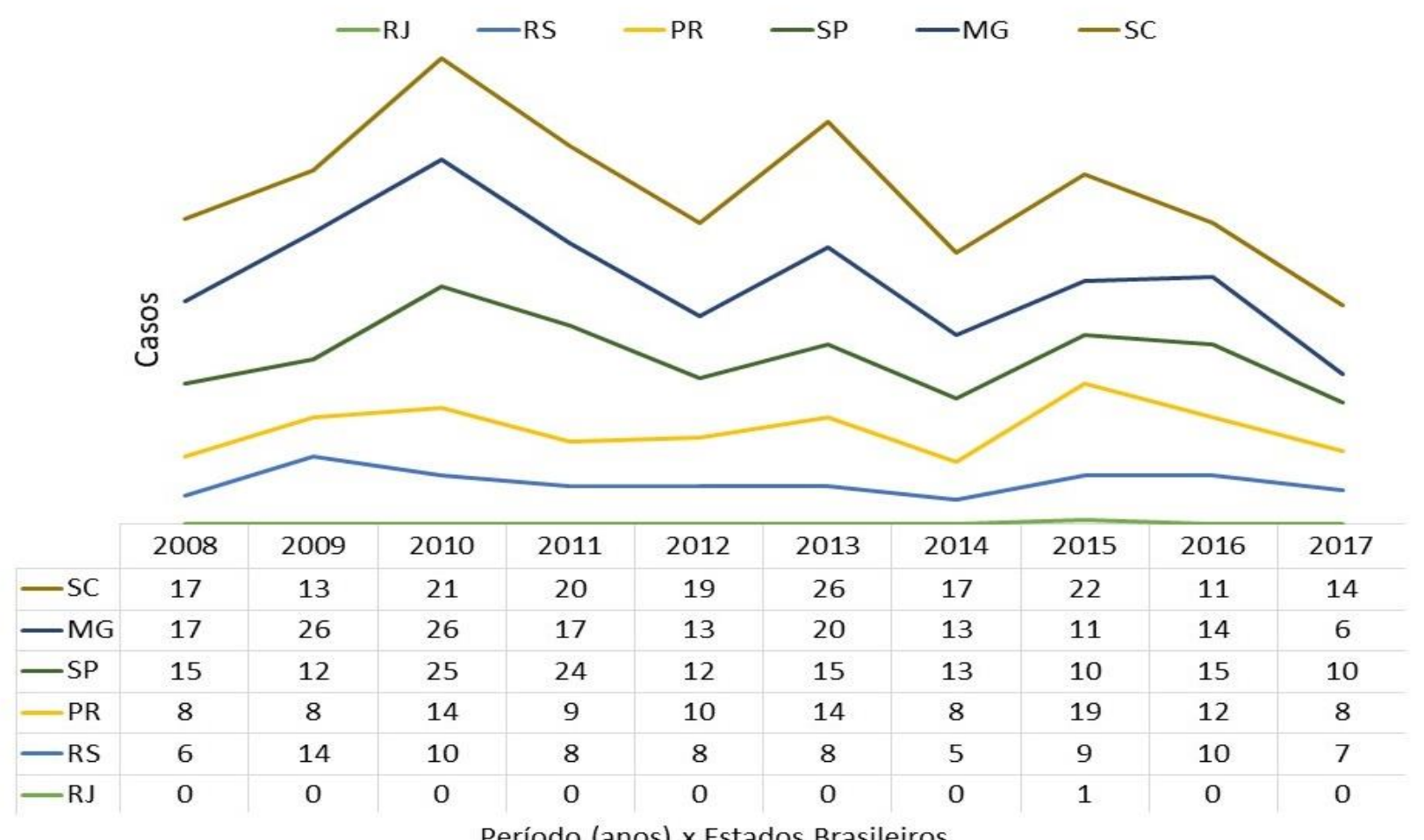

Fonte: Moura PF, et al., 2021; dados extraídos do SINAN. 
Figura 5 - Distribuição dos estados brasileiros em relação à incidência de Hantavirose e o índice de desmatamento em hectares no período de 2008 a 2017.

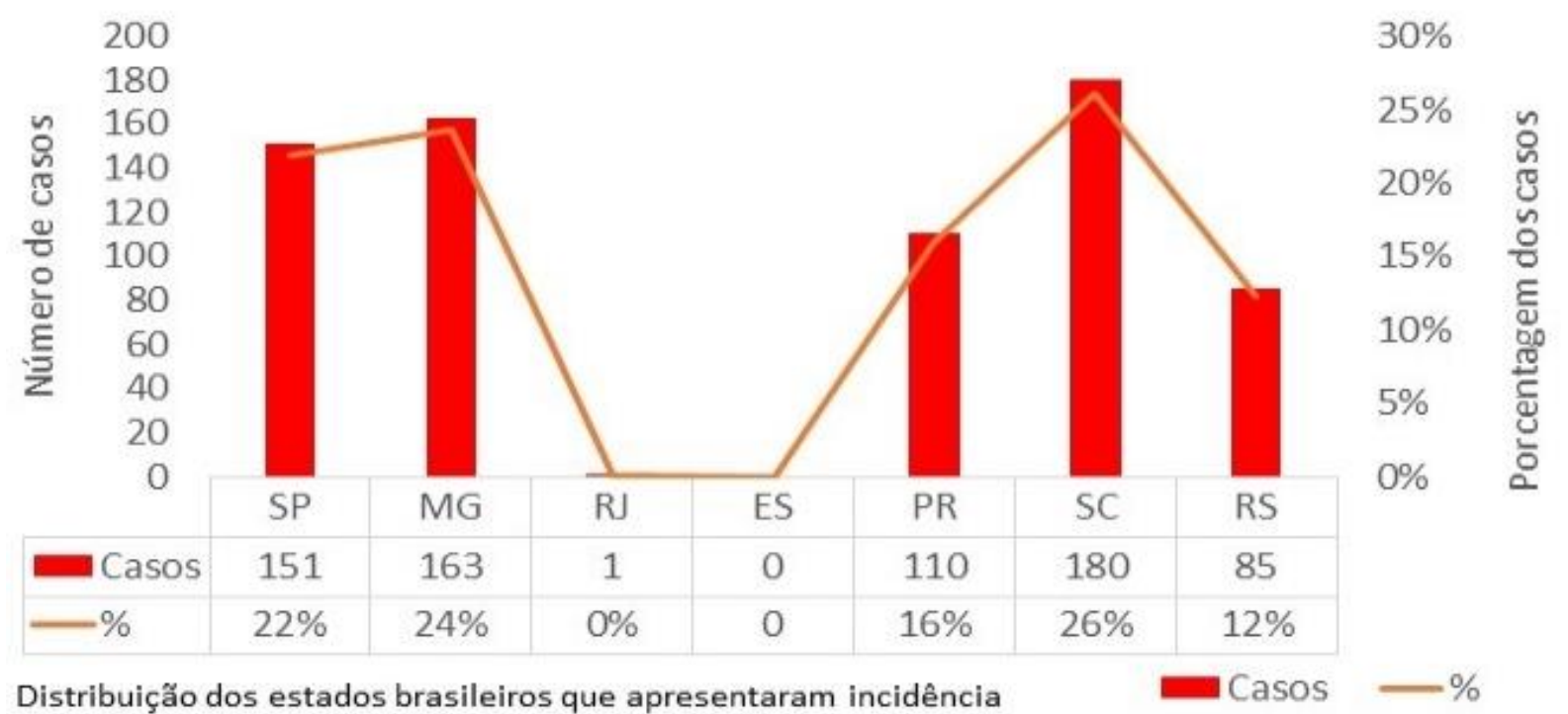

Distribuição dos estados brasileiros que apresentaram incidência

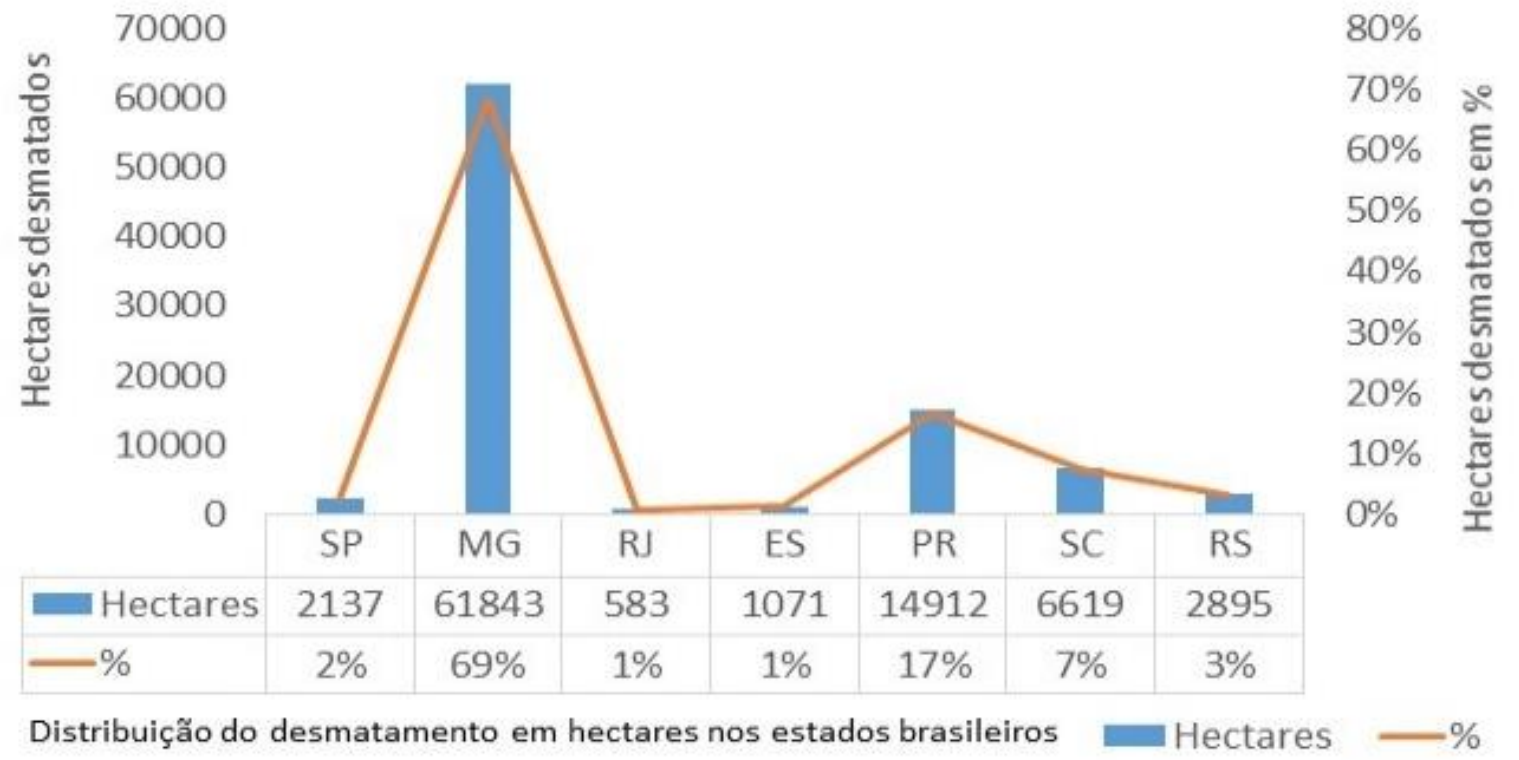

Fonte: Moura PF, et al., 2021; dados extraídos do SINAN.

\section{DISCUSSÃO}

Ao avaliar o período de estudo, de 2008 a 2017, os estados que compõem a região Sul e a Sudeste do Brasil, totalizaram 690 notificações de hantavirose. Apesar do Brasil apresentar casos em quase todos os estados, a região Sul e Sudeste sempre se destaca como maior incidência. Entre os anos de 2010 a 2020, foram notificados no país um total de 15.080 casos suspeitos, com predominância nas regiões Sul e Sudeste (MINISTÉRIO DA SAÚDE, 2021a).

Dentre os estados das regiões Sul e Sudeste, aqueles com maior número de casos foram Santa Catarina com 26\% (180/690) seguindo por Minas Gerais com 24\% (163/690). Esses resultados corroboram os achados de Fonseca LX, et al. (2018) que obtiveram para a região Sul e Centro-Oeste um total de 307 e 304 casos, respectivamente, com as regiões Centro-Oeste e Sudeste concentrando os maiores números de óbitos.

O estado de Santa Catarina também se destacou nos estudos de Silva NWF (2021), que avaliou o perfil clínico e epidemiológico dos casos confirmados de hantavirose na faixa de fronteira entre os anos de 2007 e 2017, registrando um total de 146 casos, sendo a maior ocorrência na Região Sul (67,12\%), sendo 42,47\% em Santa Catarina, $13,70 \%$ no Paraná e $10,96 \%$ no Rio Grande do Sul. 
Essa frequência maior de casos de SCPH nas regiões Sul, Sudeste e Centro-Oeste assim como em outras regiões, faz da SCPH um problema de Saúde Pública de grande importância, devido a sua alta letalidade e elevado custo social e econômico sendo necessário um sistema de vigilância epidemiológico e um diagnóstico diferencial efetivo para rastreamento dos casos e reconhecimento das áreas efetivamente de ocorrência.

Para melhor rastreamento dessas áreas, inquéritos soroepidemiológicos são importantes para conhecer a prevalência desta infecção. Neste sentido, Fernandes J, et al. (2019) coletaram amostras de sangue de trabalhadores rurais da região central do Brasil e avaliaram a presença de imunoglubulina $G(\lg G)$ para mammarenavírus e para hantavírus pelo método ELISA, encontrando 2,57\% reativos para orthohantavírus, 0,64\% para mammarenavírus e 2,1\% para arenavírus. Terças-Trettel ACP, et al. (2021) encontraram uma soroprevalência de $12,4 \%$ a $13,4 \%$ de anticorpos contra orthohantavirus em terras indígenas, na região de savana brasileira.

Dos 690 casos encontrados neste estudo, $40 \%$ evoluíram para óbito enquanto $57 \%$ evoluíram para cura. Portanto, a taxa de letalidade ficou em 40\% (274/690), estando de acordo com o estabelecido pelo Manual de Vigilância e Prevenção, do Ministério da Saúde, que mostra a taxa geral de letalidade da hantavirose no Brasil em 41,5\% (MINISTÉRIO DA SAÚDE, 2021a) e, também, se enquadrou na estimativa da taxa de letalidade mundial que varia entre $35 \%$ a $50 \%$ (MUNIR N, et al. 2021). Por outro lado, ao comparar com outros países da América do Sul, como Chile com 32\%, Argentina com 12 a 40\% e Paraguai com 11,3\% a taxa de letalidade no Brasil é maior (MINISTÉRIO DA SAÚDE, 2021a).

A letalidade da hantavirose é alta pelo fato do hantavírus inibir o fator apoptótico nas células-alvo além de causar um comprometimento da integridade da barreira endotelial devido a uma resposta imune inata excessiva, que parece ter um papel central na patogênese da doença por hantavírus (MUNIR N, et al., 2021).

O quadro clínico da SCPH é inespecífico e pode iniciar com dispneia, tosse seca, cefaleia, mialgia, náuseas, vômitos e diarreia. Com a evolução da doença, o paciente pode apresentar taquicardia, edema pulmonar, insuficiência respiratória aguda e choque, alguns apresentam. Características inespecíficas como febre, dispneia, hipoxemia e infiltrado pulmonar difuso, o diagnóstico diferencial deve incluir hantavirose (SEREJO AMD, et al., 2020). Nesse sentido, Singh S, et al. (2021) ressaltam que os sintomas desenvolvidos pelo paciente podem ser semelhantes às de outras doenças infecciosas, como leptospirose e influenza no estágio pródromo.

O perfil socioepidemiológico dos casos notificados é composto por $77 \%$ dos indivíduos acometidos do sexo masculino e estavam em idade produtiva, de 20 a 39 anos, $69 \%$ deles foram infectados em área rural e $42 \%$ exerciam ocupação relacionada com atividades rurais. A associação entre os casos de hantavirose ao tipo de atividade desenvolvida parece ser um fator de risco à exposição aos vetores, roedores e/ou com suas excretas (MINISTÉRIO DA SAÚDE, 2021a; MINISTÉRIO DA SAÚDE, 2021b).

A relação entre infecção por hantavirus e o tipo de atividade ocupacional foi levantada pela metanálise feita por Ricco M, et al. (2021), na qual fica claro, através de estudos de soroprevalência que as infecções por hantavírus no mundo estão relacionadas ao trabalho rural onde os trabalhadores apresentam soroconversão pela provável interação com roedores.

De acordo com Fonseca LX, et al. (2018) nem sempre os casos de síndrome cardiopulmonar por hantavírus (SCPH) ocorrem por exposição aos locais com presença de roedores ou por contato direto ou visualização de rato silvestre morto/vivo ou seus vestígios; o desmatamento ou aragem de terra, plantio agrícola, colheita agrícola e corte de lenha, entre outros procedimentos semelhantes também contribuem para a ocorrência dos casos.

Em nosso estudo foi observado a correlação entre os casos notificados de hantavirose e o desmatamento. Nos anos onde houve uma queda significativa no desmatamento (2014 e 2017) os casos de hantavirose diminuíram. Alterações excessivas de um habitat causadas pelo extrativismo ou pela propagação habitacional gera o aumento de infecções de origem enzoóticas, como a hantavirose em humanos (MINISTÉRIO DA SAÚDE, 2021a). Além disso, o cultivo de cana-de-açúcar entre outras culturas promove grandes efeitos sobre a paisagem facilitando a ocorrência de espécies generalistas de roedores que servem como hospedeiro para o agente da SCPH (PRIST PR, et al., 2017). 
Prist PR, et al. (2016) avaliaram dois grandes biomas do estado de São Paulo, o cerrado e a mata atlântica e chegaram à conclusão que o risco de hantavirose aumentou em ambos os biomas de acordo com o aumento de terra cultivada para cana-de-açúcar. Por outro lado, Brito MG, et al. (2020) analisaram a distribuição de 193 casos autóctones de HCPS entre 1998 e 2007, associando com a configuração paisagística na região do Cerrado mineiro e notaram que os casos de HCPS estavam mais associados ao aumento da área de pastagens plantadas e florestas naturais na região do Cerrado do que os cultivos de arroz, feijão, milho e cana-de-açúcar.

A degradação ambiental levou a uma diminuição da mata nativa, alterações nos diferentes biomas e nas mudanças antropogênicas, passando a utilizar a terra para plantio de diferentes culturas, aumentando a abundância das espécies reservatórias de Hantavírus e, consequentemente, ampliando o risco de infecção pela população (PRIST PR, et al., 2016; PRIST PR, et al., 2017).

O Atlas dos Remanescentes Florestais da Mata Atlântica elaborado pela fundação Mata Atlântica e pelo INPE, aponta que no ano de 2017 houve o menor valor total (5711 hectares) de desmatamento da série histórica do monitoramento, também demonstra que a última queda ocorreu no ano de 2014 (7354 hectares), fato que impacta diretamente na diminuição das ocorrências da hantavirose, pois estes mesmos anos apresentam os menores números de casos, 45 e 56, respectivamente (MINISTÉRIO DA CIÊNCIA, TECNOLOGIA, INOVAÇÕES E COMUNICAÇÕES e INSTITUTO NACIONAL DE PESQUISAS ESPACIAIS, 2019).

Dentre os resultados deste estudo, observou-se que os estados que apresentam maiores índices de desmatamento, Minas Gerais com 69\%, Paraná com 17\% e Santa Catarina com 7\% também possuem maior incidência de casos. Embora a doença se manifeste em todo país, as regiões Sul e Sudeste registram o maior número de casos notificados (FONSECA LX, et al., 2018; GUEDES LS, et al., 2019). Já os estados com menores índices de desmatamento, também é possível observar uma menor notificação de casos da doença; neste contexto se encaixam os estados do Espirito Santo e Rio de Janeiro, com 0 e 1 caso, respectivamente.

De acordo com Prist PR, et al. (2021), o reflorestamento das áreas degradadas, pode reduzir a abundância dos roedores reservatórios, diminuindo a chance de transmissão de SCPH ao comparar a abundância estimada entre dois cenários, foi estimado que a restauração florestal pode reduzir a abundância de $O$. nigripes em até $89,29 \%$ em $43,43 \%$ do território da Mata Atlântica e para $N$. lasiurus, a abundância diminuiu até $46 \%$ em $44 \%$ da mata atlântica.

A degradação ambiental com diminuição da área florestal, fragmentação de biomas e as mudanças antropogênicas no uso da terra como o uso de áreas de mata para plantio de diferentes culturas aumentam a abundância das espécies reservatórias de Hantavírus e consequentemente, aumentando o risco de infecção pela população. Se houver reflorestamento das áreas degradadas, pode-se reduzir a abundância dos roedores reservatórios, diminuindo a chance de transmissão de SCPH (PRIST PR, et al., 2016; PRIST PR, et al., 2017; PRIST PR, et al., 2021).

Alterações ecológicas têm grande impacto na ocorrência da doença em áreas urbanas. A expansão imobiliária parece estar diretamente associada ao transbordamento do vírus para áreas urbana, pois é comum nestes empreendimentos a substituição da vegetação natural por plantas de interesse comercial, fornecendo aos reservatórios tanto uma nova fonte de alimentação como também de abrigo. Esta condição, associada à biologia reprodutiva do reservatório, cria um ambiente propício para o contato com roedores portadores do hantavírus com o homem. O contato do homem com os roedores reservatórios, promovendo a infecção e o desenvolvimento de SCPH, é em geral nas áreas de plantio de alguma cultura agrícola (OLIVEIRA SV, et al., 2015; PINTO JUNIOR V, et al., 2020).

\section{CONCLUSÃO}

Neste estudo pode-se observar que o desmatamento que ocorre nos estados das regiões sul e sudeste está diretamente relacionado com as manifestações da hantavirose, especialmente nos anos de 2011, 2014 e 2017. Os estados que mais sofrem com a degradação ambiental apresentam os maiores números de casos, assim como, aqueles em que há menor degradação ambiental demonstram menor incidência da doença. Devese ressaltar que a hantavirose é uma doença infecciosa que resulta em alta taxa de hospitalização e de 
letalidade, sobretudo em pacientes que não recebem tratamento prévio adequado. Existe a imprescindibilidade de realizar ações direcionadas para os programas de vigilância epidemiológica, e fortalecer a amplificação de medidas preventivas e de tratamentos eficazes nas regiões que mais notificam casos deste agravo. A investigação das causas ecológicas e ambientais é de extrema importância para se compreender melhor a infecção, e assim integralizarna saúde pública melhores conhecimentos desta zoonose emergente. Dessa maneira, é viável que as atividades de informação e conscientização da população sobre o risco da degradação ambiental seja contínua e permanente.

\section{REFERÊNCIAS}

1. BRITO MG, et al. Association between hantavirus cardiopulmonary syndrome in humans and landscape configuration in the Cerrado region of Minas Gerais, Brazil. Acta Veterinaria Brasilica, 2020; 14: 201-208.

2. FERNANDES J, et al. Rodent-borne viruses survey in rural settlers from Central Brazil. Mem Inst Oswaldo Cruz, 2019; 114: 1-5.

3. FONSECA LX, et al. Magnitude e distribuição dos óbitos por hantavirose no Brasil, 2007-2015. Epidemiologia e Serviços de Saúde, 2018; 27(2): 2-11.

4. GUEDES LS, et al. Atualização do perfil epidemiológico da hantavirose no Brasil. Revista Contexto e Saúde, $2019 ; 19$ (36): 127-132.

5. MINISTÉRIO DA CIÊNCIA, TECNOLOGIA, INOVAÇÕES E COMUNICAÇÕES. Atlas dos Remanescentes Florestais da Mata Atlântica. Brasil, 2020. Disponível em: https://www.sosma.org.br/wp-content/uploads/2019/05/Atlas-mataatlantica_17-18.pdf.Acesso em: 29 de Setembro de 2020.

6. MINISTÉRIO DA SAÚDE. Hantavirose: o que é, causas, sintomas, tratamento, diagnóstico e prevenção, 2021. Brasília - DF: Brasil, 2021a. Disponível em: antigo.saude.gov.br/saude-de-a-z/hantavirose. Acesso em: 17 de Novembro de 2021.

7. MINISTÉRIO DA SAÚDE. Doenças tropicais negligenciadas. Boletim Epidemiológico, No Especial. Brasília - DF: Brasil, 2021b. Disponível em: https://www.gov.br/saude/ptbr/media/pdf/2021/marco/3/boletim_especial_doencas_negligenciadas.pdf. Acesso em: 17 de Novembro de 2021 .

8. MUNIR N, et al. Hantavirus diseases pathophysiology, their diagnostic strategies and therapeutic approaches: A review. Clinical and Experimental Pharmacology and Physiology, 2021; 48: 20-34.

9. OLIVEIRA SV, et al. Vulnerability of Brazilian municipalities to hantavirus infections based on multi-criteria decision analysis. Emerging Themes in Epidemiology, 2015; 12(15): 2-8.

10. PINTO JUNIOR VL, et al. Hantavirose no Brasil: aspectos clínicos e epidemiológicos de uma doença emergente grave. In: CARVALHO, Clarice Maia et al (Org.). Atualidades em medicina tropical no Brasil: microbiologia. Rio Branco: Stricto Sensu, 2020. p.154-174.

11. PRIST PR, et al. Landscape, environmental and social predictors of Hantavirus risk in São Paulo, Brazil. PLOS ONE, 2016; 11(10): 1-18.

12. PRIST PR, et al. Climate change and sugarcane expansion increase Hantavirus infection risk. PLoS Neglected Tropical Diseases, 2017; 11(7): 1-20.

13. PRIST PR, et al. Moving to healthier landscapes: Forest restoration decreases the abundance of Hantavirus reservoir rodents in tropical forests. Science Of The Total Environment, 2021; 752: 141-967.

14. RICCO M, et al. Occupational Hantavirus Infections in Agricultural and Forestry Workers: A Systematic Review and Metanalysis. Viruses. 2021; 13(2150): 1-25.

15. SEREJO AMD, et al. Hantavírus e síndrome cardiopulmonar. Relato de caso no entorno do distrito federal. Brasília Médica, 2020; 57: 1-7.

16. SILVA NWF. Hantavirus in the Brazilian borderland strip: clinical-epidemiological profile of confirmed cases in Brazil. 2007 to 2017. Archives of Health, 2021; 2(4): 810-814.

17. SINGH S, et al. Epidemiology, virology and clinical aspects of hantavirus infections: an overview. International Journal of Environmental Health Research, 2021; 29(6): 1-13.

18. TERÇAS-TRETTEL ACP, et al. Orthohantavirus Survey in Indigenous Lands in a Savannah-Like Biome, Brazil. Viruses $2021 ; 13(1122): 1-11$. 